in-hospital mortality; careful selection of oxygen saturation targets in clinical practice is also warranted.

Waldemar A. Carlo, M.D.

University of Alabama at Birmingham

Birmingham, AL

wcarlo@peds.uab.edu

Neil N. Finer, M.D.

University of California at San Diego

San Diego, CA

Marie G. Gantz, Ph.D.

RTI International

Research Triangle Park, NC
Since publication of their article, the authors report no further potential conflict of interest.

1. Duc G, Sinclair JC. Oxygen administration. In: Sinclair JC, Bracken MB, eds. Effective care of the newborn infant. New York: Oxford University Press, 1992:178-94.

2. Askie LM, Henderson-Smart DJ, Ko H. Restricted versus liberal oxygen exposure for preventing morbidity and mortality in preterm or low birth weight infants. Cochrane Database Syst Rev 2009;1:CD001077.

3. Tin W, Gupta S. Optimum oxygen therapy in preterm babies. Arch Dis Child Fetal Neonatal Ed 2007;92:F143-F147.

4. Laptook AR, Shalhab W, Allen J, Saha S, Walsh M. Pulse oximetry in very low birth weight infants: can oxygen saturation be maintained in the desired range? J Perinatol 2006;26:337-41.

\title{
A Step-up Approach, or Open Necrosectomy for Necrotizing Pancreatitis
}

TO THE EDITOR: The results from the study by van Santvoort et al. (Minimally Invasive Step-up Approach versus Maximal Necrosectomy in Patients with Acute Necrotizing Pancreatitis [PANTER]) (April 22 issue) ${ }^{1}$ show that percutaneous drainage (PCD) alone is a valuable strategy in selected patients, helping to avoid the need for surgery in $40 \%$ of step-up patients.

The reduced morbidity associated with the procedure may largely be due to the avoidance of harm from surgery: when PCD-only patients are not considered, the complication rate appears to be similar in the two study groups. Moreover, PCD was often inadequate, leading to a delay in source control. Since PCD appears to be less successful in patients with multiple organ failure, ${ }^{2}$ and since mortality dramatically increased when it was used as a sole strategy for these patients, ${ }^{3}$ an important element of the treatment is potentially delayed. Early identification of patients who will not be helped by PCD is desirable.

Rather than using a step-up approach for all patients, a strategy tailored to the patient's specific needs, based on the results of computed tomography and on clinical condition, using the source-control strategy most likely to adequately drain collected fluid and débride infected necrotic tissue may be the best approach after all. PCD, video-assisted retroperitoneal débridement, and open necrosectomy may all be effective tools to use in reaching this goal.

\footnotetext{
Jan J. De Waele, M.D., Ph.D.

Ghent University Hospital

Ghent, Belgium

jan.dewaele@ugent.be
}

No potential conflict of interest relevant to this letter was reported.

1. van Santvoort HC, Besselink MG, Bakker OJ, et al. A step-up approach or open necrosectomy for necrotizing pancreatitis. N Engl J Med 2010;362:1491-502.

2. Mortelé KJ, Girshman J, Szejnfeld D, et al. CT-guided percutaneous catheter drainage of acute necrotizing pancreatitis: clinical experience and observations in patients with sterile and infected necrosis. AJR Am J Roentgenol 2009;192:110-6.

3. Rocha FG, Benoit $\mathrm{E}$, Zinner MJ, et al. Impact of radiologic intervention on mortality in necrotizing pancreatitis: the role of organ failure. Arch Surg 2009;144:261-5.

TO THE EDITOR: The PANTER study group teaches us that "minimally" invasive surgery is associated with a lower morbidity than open necrosectomy in patients who have necrotizing pancreatitis with infected necrotic tissue. Although this article is a milestone in the surgical literature, its results are disappointing. There was no significant difference in the mortality of the two study groups $(16 \%$ vs. $19 \%)$ despite the fact that intervention was withheld for at least 4 weeks. The complications in the group receiving "minimally" invasive treatment included enterocutaneous fistulas (in $22 \%$ of patients), intra-abdominal bleeding (16\%), pancreatic fistulas (28\%), and incisional hernias (7\%). ${ }^{1}$ The surgery these patients received was clearly not "minimally" invasive.

But is there another approach? Does infected necrotic tissue need drainage at all? Several case reports and series have recorded reasonable survival rates among patients treated with antibiotics alone. ${ }^{1-4}$ Now that withholding intervention for at least 4 weeks seems to be ensconced in good surgical practice, perhaps a longer wait, coupled with the judicious use of antibiotics, can 
further reduce mortality and the need for any invasive intervention.

\section{William M. Steinberg, M.D.}

Rockville Internal Medicine Group

Rockville, MD

No potential conflict of interest relevant to this letter was reported.

1. Baril NB, Ralls PW, Wren SM, et al. Does an infected peripancreatic fluid collection or abscess mandate operation? Ann Surg 2000;231:361-7.

2. Dubner $\mathrm{H}$, Steinberg $\mathrm{W}$, Hill M, et al. Infected pancreatic necrosis and peripancreatic fluid collections: serendipitous response to antibiotics and medical therapy in three patients. Pancreas 1996;12:298-302.

3. Adler DG, Chari ST, Dahl TJ, Farnell MB, Pearson RK. Conservative management of infected necrosis complicating severe acute pancreatitis. Am J Gastroenterol 2003;98:98-103.

4. Runzi M, Niebel W, Goebell H, Gerken G, Layer P. Severe acute pancreatitis: nonsurgical treatment of infected necroses. Pancreas 2005;30:195-9.

THE AUTHORS REPLY: We first want to clarify several issues discussed by Dr. Andrew Warshaw in the editorial he wrote about our article. ${ }^{1}$ Warshaw stated that the step-up approach has narrow applicability. This is not correct. The feasibility of the step-up approach was $98 \%$, with just one patient excluded because a drain could not be placed. Warshaw also stated that the feasibility of using a retroperitoneal access route was a criterion for inclusion in the trial. This was not the case: percutaneous or endoscopic catheter drainage of fluid could proceed through any route (retroperitoneal, transabdominal, or endoscopic transgastric). Nevertheless, a retroperitoneal access route for drainage, and if needed, video-assisted retroperitoneal débridement, was possible in 80 of the 88 patients (91\%) who underwent randomization. It was also noted that the rate of death in our study (17\%) compares unfavorably to rates in recent North American studies. ${ }^{2,3}$ This difference can probably be attributed to differences in case mix, since these studies showed lower percentages of infected necrotic tissue (72 to $74 \%$ vs. $92 \%$ ) and lower preoperative scores on the Acute Physiology and Chronic Health Evaluation (APACHE) II ( 9.0 to 9.5 vs. 15). Notably, in the Boston study referenced by Warshaw, the rate of death among patients with infected necrotic tissue (i.e., the subgroup similar to that in our study) was $15 \% .^{3}$

In his letter, De Waele suggests that PCD was often inadequate, leading to a delay in source control. However, we do not consider PCD to have failed when surgery is still needed. PCD is appreciated as a means of stabilizing sepsis and thereby improving the patient's condition for subsequent surgery. Basing his remarks on retrospective studies, De Waele also suggests that PCD is less successful in patients with multipleorgan failure. In our study, PCD was successful in $35 \%$ of patients, irrespective of single or multiple organ failure. It is also suggested that mortality increases dramatically when PCD is used as a sole strategy. This was not the case in our study: the rate of death among patients undergoing PCD only was $12 \%$ (2 patients of 17 ) as compared with $23 \%$ (6 of 26) among those undergoing PCD and surgery. We therefore conclude that PCD should be the first treatment whenever possible.

Steinberg suggests that the mortality rate in our study is disappointing. However, recent series from expert centers in Boston and Liverpool show similar mortality rates. ${ }^{3,4}$ We agree that a very small subgroup of patients with infected necrotic tissue might be treated with antibiotics alone, but this approach has been discussed only in case reports and very small series, and multiple-organ failure still develops in these patients. ${ }^{5}$ In our study, a nationwide multidisciplinary expert panel agreed on the indication for intervention in each patient.

\section{Hjalmar C. van Santvoort, M.D.}

Marc G. Besselink, M.D., Ph.D.

University Medical Center, Utrecht

Utrecht, the Netherlands

\section{Hein G. Gooszen, M.D., Ph.D.}

Radboud University Nijmegen Medical Center Nijmegen, the Netherlands h.gooszen@ok.umcn.nl

Since publication of their article, the authors report no further potential conflict of interest.

1. Warshaw AL. Improving the treatment of necrotizing pancreatitis — a step up. N Engl J Med 2010;362:1535-7.

2. Howard TJ, Patel JB, Zyromski N, et al. Declining morbidity and mortality rates in the surgical management of pancreatic necrosis. J Gastrointest Surg 2007;11:43-9.

3. Rodriguez JR, Razo AO, Targarona J, et al. Debridement and closed packing for sterile or infected necrotizing pancreatitis: insights into indications and outcomes in 167 patients. Ann Surg 2008;247:294-9.

4. Raraty MG, Halloran CM, Dodd S, et al. Minimal access retroperitoneal pancreatic necrosectomy: improvement in morbidity and mortality with a less invasive approach. Ann Surg 2010; 251:787-93.

5. Runzi M, Niebel W, Goebell H, Gerken G, Layer P. Severe acute pancreatitis: nonsurgical treatment of infected necroses. Pancreas 2005;30:195-9. 